\title{
RIVER MORPHOLOGY MONITORING OF A SMALL-SCALE ALPINE RIVERBED USING DRONE PHOTOGRAMMETRY AND LIDAR
}

\author{
D. Backes ${ }^{1,2^{*}}$, M. Smigaj ${ }^{3,4}$, M. Schimka ${ }^{5}$, V. Zahs ${ }^{5}$, A. Grznárová ${ }^{6}$, M. Scaioni $^{7}$ \\ ${ }^{1}$ Department of Engineering, University of Luxembourg, Luxembourg - dietmar.backes@uni.lu \\ 2 Dept. of Civil, Environmental and Geomatic Engineering, University College London, UK - d.backes@ucl.ac.uk \\ ${ }^{3}$ School of Civil Engineering and Geosciences, Newcastle University, UK - magdalena.smigaj@newcastle.ac.uk \\ ${ }^{4}$ JSPS International Research Fellow, Faculty of Agriculture, Kyushu University, Japan - magdalena.smigaj.422@m.kyushu-u.ac.jp \\ 5 3DGeo Research Group, Institute of Geography, Universität Heidelberg, Germany - (schimka, zahs)@ stud.uni-heidelberg.de \\ ${ }^{6}$ Department of Forest Management and Geodesy, Technical University in Zvolen, Slovakia - alzbeta.grznarova@tuzvo.sk \\ ${ }^{7}$ Department of Architecture, Built Environment and Construction Engineering, Politecnico Milano, Italy - marco.scaioni@ polimi.it
}

\section{Commission II, WG II/10}

KEY WORDS: UAV photogrammetry, UAV-borne LiDAR, unmanned laser scanning ULS, spatio-temporal change detection, LiDAR simulations

\begin{abstract}
:
An efficient alternative to labour-intensive terrestrial and costly airborne surveys is the use of small, inexpensive Unmanned Aerial Vehicles (UAVs) or Remotely Piloted Aerial Systems (RPAS). These low-altitude remote sensing platforms, commonly known as drones, can carry lightweight optical and LiDAR sensors. Even though UAV systems still have limited endurance, they can provide a flexible and relatively inexpensive monitoring solution for a limited area of interest. This study investigated the applicability of monitoring the morphology of a frequently changing glacial stream using high-resolution topographic surface models derived from low-altitude UAV-based photogrammetry and LiDAR. An understanding of river-channel morphology and its response to anthropogenic and natural disturbances is imperative for effective watershed management and conservation. We focus on the data acquisition, processing workflow and highlight identified challenges and shortcomings. Additionally, we demonstrate how LiDAR data acquisition simulations can help decide which laser scanning approach to use and help optimise data collection to ensure full coverage with desired level of detail. Lastly, we showcase a case study of 3D surface change analysis in an alpine stream environment with UAV-based photogrammetry. The datasets used in this study were collected as part of the ISPRS Summer School of Alpine Research, which will continue to add new data layers on a biyearly basis. This growing data repository is freely available for research.
\end{abstract}

\section{INTRODUCTION}

\subsection{Monitoring river morphology}

River-channel morphology influences flow, flooding patterns, rates of erosion, sediment transport and deposition. An understanding of channel morphology and its response to anthropogenic and natural disturbances is imperative for effective watershed management and conservation. Alterations in channel pattern can serve as an indicator of the environmental health of a watershed. For instance, changes in bar morphology (non-vegetated accumulations of sediment often developing on channel's sides) usually indicate variations in upstream sediment supply (Hogan, Luzi, 2010; Longoni et al., 2016).

Traditionally, channel morphology has been characterised through labour-intensive topographic surveys using total stations, and more recently RTK-GNSS receivers. However, the use of such equipment is restricted to easily accessible sites, which are relatively shallow and slow flowing. Furthermore, these methods are often impractical during high flow or flood conditions when morphological processes are most active. Remote sensing technologies have revolutionised the way topographic data are collected. In particular, airborne LiDAR allows rapid and accurate measurements of topography over large areas. Subsequently generated high spatial resolution digital elevation models (DEMs) are used for numerous applications, such as watershed mapping or flood modelling. However, due to the high expenditure and effort, airborne LiDAR is usually acquired with a low temporal frequency. This limits its use for multi-temporal analysis.

Although confined to limited areas, lightweight UAVs are a promising alternative for generating 3D data with high spatiotemporal resolution (Dall'Asta et al., 2017; Giordan et al., 2017). These are generally equipped with inexpensive off-the-shelf optical cameras, making them a cost-efficient solution. The collected imagery can be processed in modern software packages utilising Structure-from-Motion (SfM) and Multi-View-Stereo (MVS) algorithms. The quality and reliability of drone-based navigation and orientation sensors have considerably improved. Nevertheless, Ground Control Points (GCPs) are still fundamental for acquiring reliable and accurately georeferenced datasets. Previous studies documented a range of methodological challenges that need to be addressed to achieve reliable results (Eltner et al., 2016; James and Robson, 2014; Smith et al., 2016). Since these might significantly limit data suitability for the intended application, further investigations into methodological processes are needed.

In recent years, technological progress and miniaturisation of sensors, such as the appearance of high-performance, miniature inertial measurement units (IMU), enabled the development of UAV-borne LiDAR systems. Many of these unmanned laser scanning (ULS) systems are still unreliable and at an experimental stage, operating lower-grade LiDAR sensors commonly used in robotics applications. However, recent studies

* Corresponding author 
based on UAVs equipped with dedicated mapping sensors demonstrated reliable collection of topographic datasets (Babbel et al., 2019; Mayr et al., 2019). ULS can produce accurate and very high spatial resolution point clouds, enabling more detailed characterisation of bare earth and microtopographic features. While flight planning for drone-based photogrammetry is well established using standard flight patterns (see, e.g., Pepe et al., 2018), LiDAR data acquisition often follows a trial and error approach and relies heavily on the experience and expertise of the operator. The quality and effective point density of the data is dependent on the flight plan (e.g. flying height and speed) and scanner settings (e.gscan speed and scanning step width). Testing different combinations of flight patterns and parameters in the field to optimise the results would be impractical. Instead, the effect of different parameters can be investigated with dedicated simulators, such as the Heidelberg LiDAR Operations Simulator (HELIOS). HELIOS is an open-source laser scanning simulation framework (Bechthold, Höfle 2016), which enables the development of data acquisition strategies for efficient data collection based on given limitations (e.g. spatial and temporal resolution, accuracy, spatial completeness) and available resources. Additionally, it can be used to develop and test methods for 3D surface change analysis.

\subsection{Background and study site}

The presented study was carried out as part of the ISPRS Summer School of Alpine Research in Obergurgl, Austria, which is organised by the University of Innsbruck on a biyearly basis since 2015. The area of interest of this ongoing study is the foreland of the Rotmoos glacier, located near the Central Alpine Ridge in Tyrol, Austria (46.845E, 11.019 N, $2300 \mathrm{~m}$ a.s.l., Figure 2). The riverbed of the glacial stream along the valley has a highly dynamic nature and is experiencing bank erosion and frequent river channel relocation.

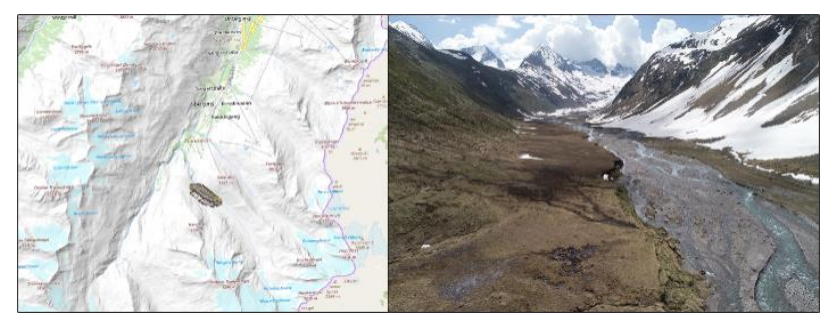

Figure 1. Study area: Rotmoos valley in the Austrian Alps

The three datasets used in this study were acquired using low-altitude UAV platforms during the ISPRS Summer Schools on "Close-range Sensing Techniques in alpine Terrain" in June 2015, June 2017 and June 2019 (Rutzinger et al., 2016; 2018; Rutzinger and Heinrich, 2019). The datasets from 2015 and 2017 were obtained from Pfeifer et al. (2017).

\subsection{Structure of the paper}

In this paper we: (1) compare point clouds derived using photogrammetric principles with UAV-based LiDAR data; (2) validate co-registration of the various datasets and assess the quality in terms of resolution, noise and completeness; (3) demonstrate how LiDAR acquisitions can be optimised using a simulator, and; (4) present a case study of 3D surface change analysis in an alpine stream environment with UAV-based photogrammetry.

\section{DATA ACQUISITION}

The Rotmoos valley was mapped using a range of low altitude UAV platforms with optical imaging sensors during successive summer school campaigns. While a fixed-wing aircraft was used for the data acquisition in 2015 and 2017, a multicopter system was deployed in 2019. Fixed-wing aircrafts have longer endurance and can cover larger areas of interest, whilst multicopter platforms are generally more stable and flexible. They also allow more precise positioning and image acquisition.

During all three campaigns highly redundant image blocks were collected, alongside accurate Ground Control Points (GCPs), suitable for generation of dense, georeferenced point clouds and topographic mapping products. In addition to optical imagery, a UAV-based LiDAR point cloud was collected in 2019 using a RIEGL RiCOPTER from the University of Innsbruck.

\subsection{Ground control}

The provision of accurate and well-distributed GCPs is still crucial requirement to achieve accurate and reliable topographic surveys using small UAVs with non-metric camera systems. However, in a quickly changing environment like the Rotmoos valley, it seems impractical or impossible to establish a permanent ground control which could serve a frequent monitoring scheme. Consequently, new GCPs were established prior to each data collection.

GCPs are usually surveyed using RTK-GNSS observations or a combination of GNSS and terrestrial surveying methods (e.g. total station). The use of survey grade RTK-GNSS equipment can provide absolute positioning accuracies below $2 \mathrm{~cm}$ in plane and height but requires dual observations for all surveyed points in order to obtain reliable results. Total station surveys on the other hand can provide higher relative accuracy between the surveyed GCPs but require initial reference points.
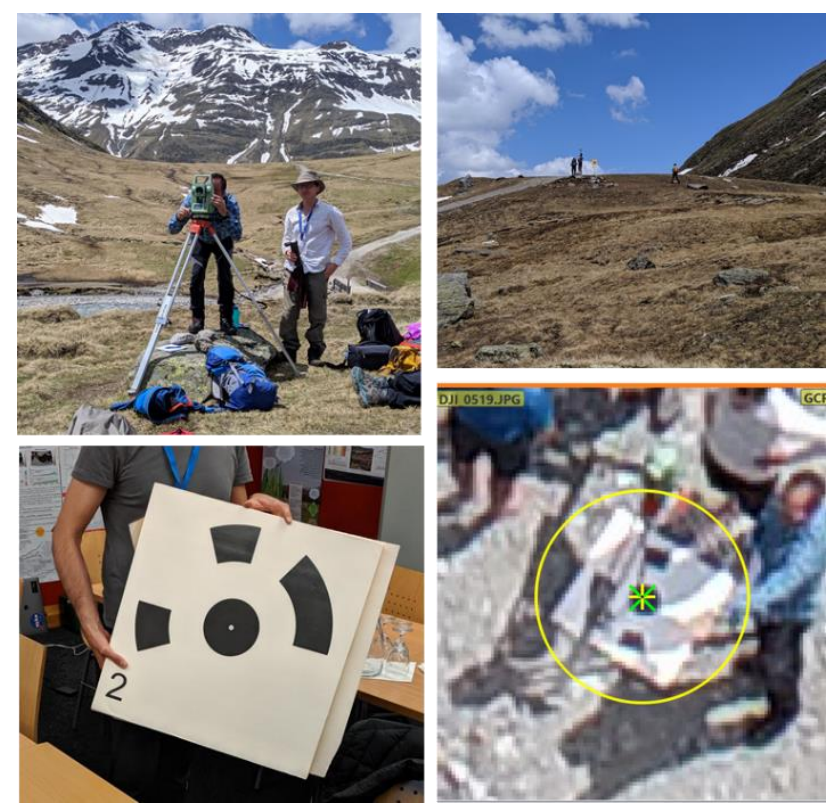

Figure 2. GCP survey

For the data acquisition in 2015, GCPs were collected using RTK-GNSS only, while a combination of RTK-GNSS and total station survey was used during subsequent campaigns in 2017 and 2019. GCPs were established as coded targets mounted on 
square Polyurethane boards of approximately $50 \times 50 \mathrm{~cm}$ (Figure 2). During the 2019 campaign, 11 GCPs were distributed around the area of interest (Figure 3). Two control points, observed using RTK-GNSS, provided a base line for a total station survey. In addition to the GCPs, additional targets were distributed around the riverbank.

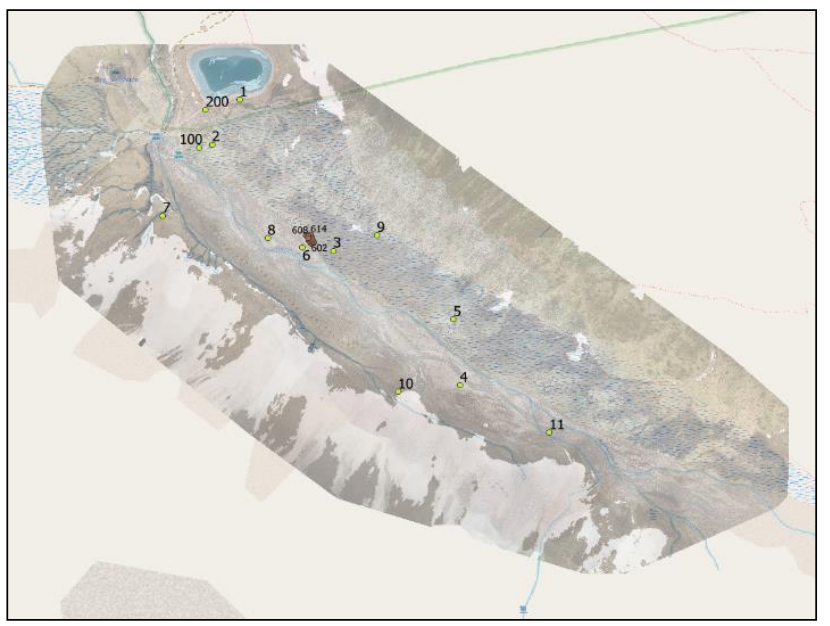

Figure 3. Distribution of GCPs for the 2019 campaign

\subsection{UAV photogrammetry}

During the fieldwork campaign in 2019, a DJI Phantom4 Pro was deployed to collect imagery over the study area. Pix4D capture software was used for flight planning and mission control. Several missions were flown to: (1) cover the entire area of interest with highly redundant image blocks; (2) focus on a particular riverbank region with high spatial resolution, and (3) collect additional oblique images. To capture a geometrically stable block, two missions were conducted at a flying height of $80 \mathrm{~m}$ following flight lines along the valley and at $100 \mathrm{~m}$ altitude with flight lines perpendicular to the first mission. Both flights were then combined into a single block with cross-flight pattern (Figure 4). Overall, 339 images were captured with $70 \%$ forward and $60 \%$ side overlap with the camera pointing nadir.
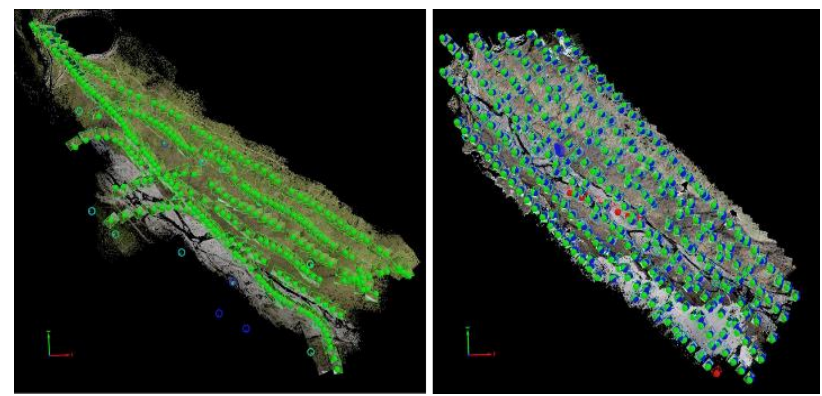

Figure 4. Photogrammetric blocks acquired in 2015 using a fixed-wing platform (left) and in 2019 using a multicopter platform (right).

A Sony Nex-5 camera was used onboard a fixed-wing aircraft in 2015 and 2017. Figure 4 shows the relatively unstable flight lines of the fixed-wing aircraft, highlighting the challenge of collecting image blocks under windy weather conditions. Many images lacked quality and experienced motion blur. Furthermore, the left riverbank was only partially captured during this initial campaign.

\subsection{UAV-borne LiDAR acquisition}

In addition to the image acquisition during the fieldwork campaign in June 2019, a UAV-borne LiDAR dataset was acquired using a RIEGL RiCOPTER with a VUX-1LR laser scanner and a Trimble/Applanix AP20 IMU/GNSS unit. This system was also equipped with two side-looking Sony Alpha 6000 cameras enabling generation of RGB textured point clouds. The flight plan was designed to follow the riverbanks in a forward and backward path at an altitude of approximately 100 $\mathrm{m}$ (Figure 5). The images acquired by the side-looking cameras were also utilised for UAV photogrammetry as a separate photogrammetric block as well as in combination with Phantom4 imagery.
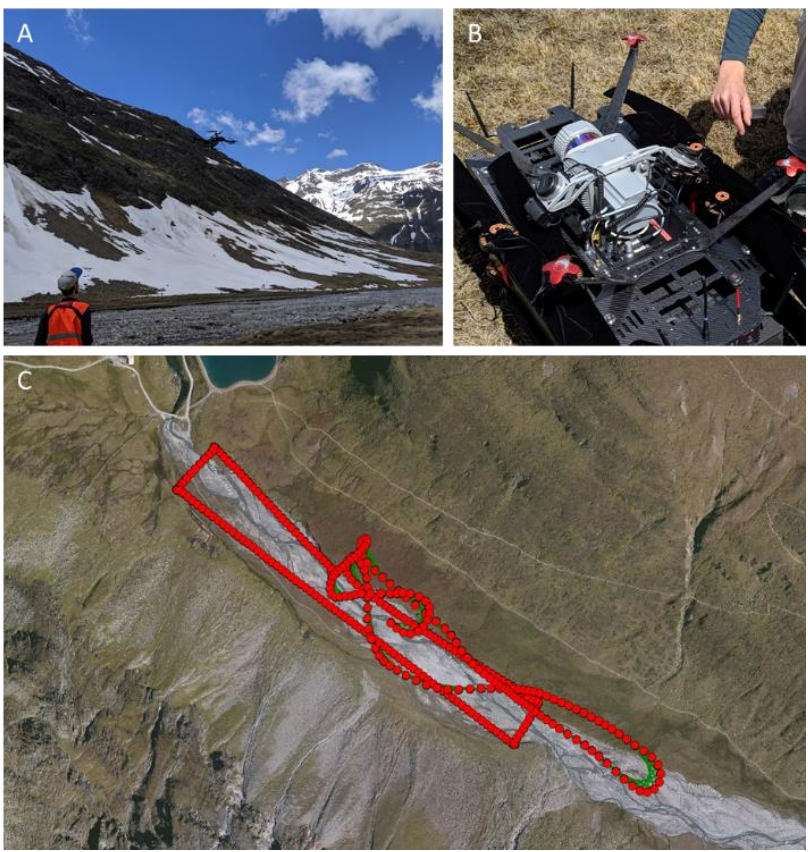

Figure 5. RiCOPTER flight mission (A), sensor configuration with two side-looking looking cameras (B) and flight path (C).

\section{POST-PROCESSING AND CHANGE DETECTION}

\subsection{Photogrammetric workflows}

Two commercial software packages, Pix4D Mapper and Agisoft Metashape, were used to compute the image orientation of the data and to subsequently generate 3D surface representations via dense image matching. These software packages deploy a combination of SfM and MVS algorithms.

bundle block adjustment (BBA) were calculated for four sets of imagery: (1) fixed-wing imagery from 2015; (2) Phantom4 imagery from 2019; (3) RiCOPTER imagery from 2019, and (4) a combination of Phantom 4 and RiCOPTER imagery from 2019. To highlight the differences in data acquisition, the photogrammetric block from 2015 was reprocessed alongside the imagery from 2019. Key parameters of these image acquisition campaigns are summarised in Table 1.

Photogrammetric post-processing followed a stepwise approach. After initial image orientation, GCPs were added to the BBA. A thorough quality assessment was conducted before dense image matching algorithms were applied to extract dense point clouds. Finally, Digital Surface Models (DSMs) and orthophotos were derived. No a-priori exterior orientation parameters were 
available for the images acquired in 2015, adding to the computational complexity. All BBA included camera selfcalibration, requiring a sufficient number of well-distributed and accurate GCPs.

\begin{tabular}{|c|l|c|c|c|}
\hline Date & $\begin{array}{l}\text { Platform and } \\
\text { Sensor }\end{array}$ & Img. & $\begin{array}{c}\text { Flying } \\
\text { height (m) }\end{array}$ & $\begin{array}{c}\text { Average } \\
\text { GSD }(\mathrm{cm})\end{array}$ \\
\hline $07 / 2015$ & Fixed-wing & 260 & 100 & 2.95 \\
& Sony NEX-5 & & & \\
& 16 mm lens & & & \\
& Fixed-wing & 254 & 90 & $\sim 3$ \\
& Sony NEX-5 & & & \\
& 16 mm lens & & & \\
& Multicopter & 226 & 80 & 2.04 \\
& DJI Phantom4 & 106 & 100 & 2.58 \\
& 8.8mm lens & \multirow{6}{*}{604} & 100 & 2.98 \\
& Multicopter & & & \\
& RiCOPTER & & & \\
& Sony Alpha 6000 & & & \\
& 16 mm lens & & & \\
\hline
\end{tabular}

Table 1. Properties of image acquisitions

\subsection{UAV-borne LiDAR}

\subsubsection{Post-processed point cloud}

Processing ULS data is a complex procedure requiring technical expertise and in-depth knowledge about its components. Accurate computation of the flight trajectory is key for the quality of the final point cloud. This processing was carried out by Magnus Bremer from the Remote Sensing and Geomatics group of the Austrian Academy of Science; the results were checked against a ground control field. The ULS flight captured a highdensity point cloud with approximately 92 million points (average point density of $1560 / \mathrm{m}^{2}$ ), suitable for capturing microtopographic features (Figure 6). Voids were present only in snow-covered areas and standing water surfaces. With a ranging accuracy of $1 \mathrm{~cm}$ and a typical positional accuracy of $5 \mathrm{~cm}$, the system provides superior topographic data and was used as a reference dataset.
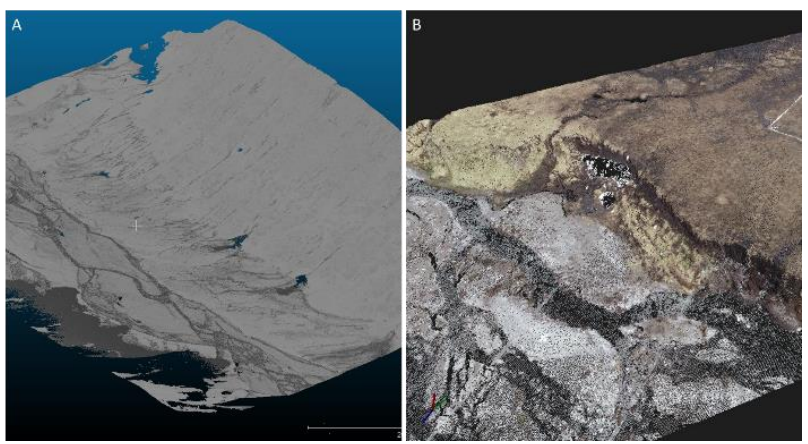

Figure 6. LiDAR DSM of the Rotmoos Valley (A); example of fine detail in the RGB textured LiDAR point cloud (B).

\subsubsection{Simulation of LiDAR data acquisitions}

To illustrate the use of HELIOS for optimising data collection, data acquisitions in the Rotmoos valley with two different LiDAR sensors were simulated using the parameters shown in Table 2. Riegl VUX-1UAV was simulated to be onboard a multicopter flying at a height of $100 \mathrm{~m}$ and a velocity of $6 \mathrm{~m} / \mathrm{s}$. As an alternative, a terrestrial survey using a Riegl VZ-400 based on multiple locations along the river-channel were simulated. A DSM derived from the 2019 Phantom 4 campaign was used as input. The simulations required high computational effort; therefore, the input terrain model was decreased to $1 / 10$ of its original size. We followed an empirical and iterative approach to optimise flight trajectories for the UAV-borne survey and scanning positions for the terrestrial survey.

\begin{tabular}{|c|c|c|c|c|}
\hline Sensor & $\begin{array}{c}\text { Pulse } \\
\text { frequency } \\
(\mathrm{kHz})\end{array}$ & $\begin{array}{c}\text { Scan } \\
\text { frequency } \\
(\mathrm{Hz})\end{array}$ & $\begin{array}{c}\text { Hz. res. } \\
(\mathrm{deg})\end{array}$ & $\begin{array}{c}\text { V.res. } \\
(\mathrm{deg})\end{array}$ \\
\hline $\begin{array}{c}\text { Riegl } \\
\text { VUX-1UAV } \\
\text { Riegl } \\
\text { VZ-400 }\end{array}$ & 550 & 200 & 0.036 & 0.073 \\
\hline
\end{tabular}

Table 2. Scanner properties used for simulations

\subsection{D surface change analysis}

The dense point clouds derived from the UAV imagery for the three investigated epochs were registered by means of Iterative Closest Point (ICP) algorithm, which was performed on stable areas close to the riverbed. The final registration RMSE was 0.15 m for both 2015-2017 and 2015-2019 epoch combinations.

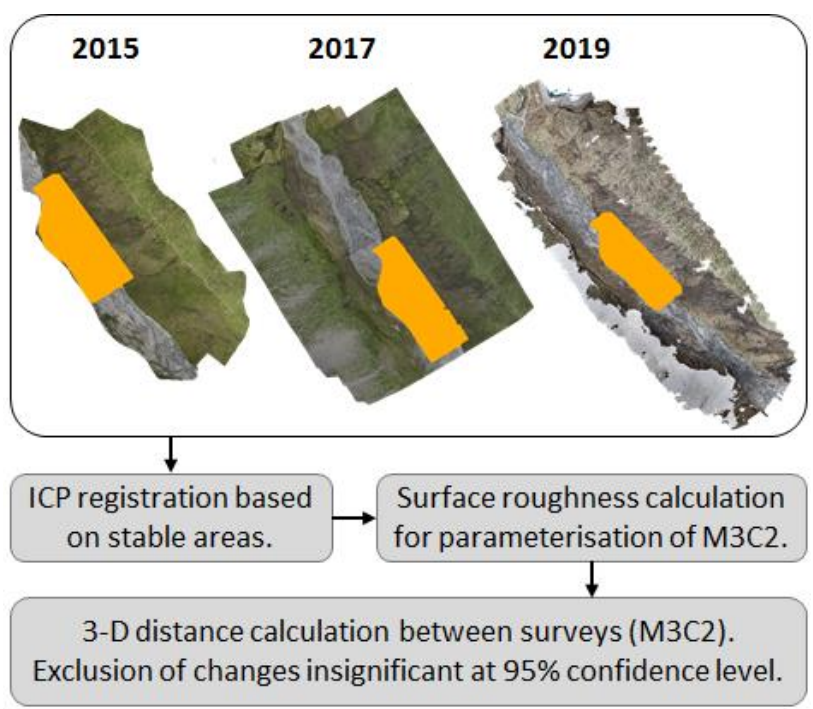

Figure 7. Overview of the change detection analysis; the area of interest is highlighted in orange.

\begin{tabular}{|l|c|c|c|c|}
\hline $\begin{array}{l}\text { Reference } \\
\text { cloud }\end{array}$ & $\begin{array}{c}\text { Data } \\
\text { Cloud }\end{array}$ & $\begin{array}{c}\text { Normal } \\
\text { scale (m) }\end{array}$ & $\begin{array}{c}\text { Projection } \\
\text { scale (m) }\end{array}$ & $\begin{array}{c}\text { Confidence } \\
\text { interval (m) }\end{array}$ \\
\hline $07 / 2015$ & $07 / 2017$ & 5.25 & 1.0 & 0.32 \\
$07 / 2017$ & $06 / 2019$ & 5.25 & 1.0 & 0.34 \\
$07 / 2015$ & $06 / 2019$ & 5.25 & 1.0 & 0.46 \\
\hline
\end{tabular}

Table 3. Epoch combinations and $\mathrm{M} 3 \mathrm{C} 2$ parameter values used for the displacement analysis

Multiscale Model-to-Model Cloud Comparison (M3C2, Lague et al. 2013) displacement analysis was then performed at different timescales to identify areas of erosion and accumulation and their temporal variability within the riverbed. The $\mathrm{M} 3 \mathrm{C} 2$ algorithm consists of two stages: (1) estimation of surface normal vector orientation and (2) calculation of the distance between two bi-temporal point clouds along the normal vector. The $\mathrm{M} 3 \mathrm{C} 2$ normal and projection scale were set here at a diameter of $5.25 \mathrm{~m}$ and $1 \mathrm{~m}$, respectively. The $\mathrm{M} 3 \mathrm{C} 2$ provides a spatially variable level of detection value that enables an approximation of the minimum detectable changes at $95 \%$ confidence. Only surface changes exceeding this level of detection were considered statistically significant. The applied change detection workflow is shown in Figure 7, whilst epoch combinations for the 
displacement analysis are summarised in Table 3 alongside used $\mathrm{M} 3 \mathrm{C} 2$ parameter values. The analysis was restricted to the riverbed area common to all three survey campaigns.

\section{RESULTS AND DISCUSSIONS}

\subsection{UAV photogrammetry}

\subsubsection{Image orientation}

The results of the BBA are summarised in Table 4 and shown in Figure 8. Overall, the achieved accuracies were within the expected range.
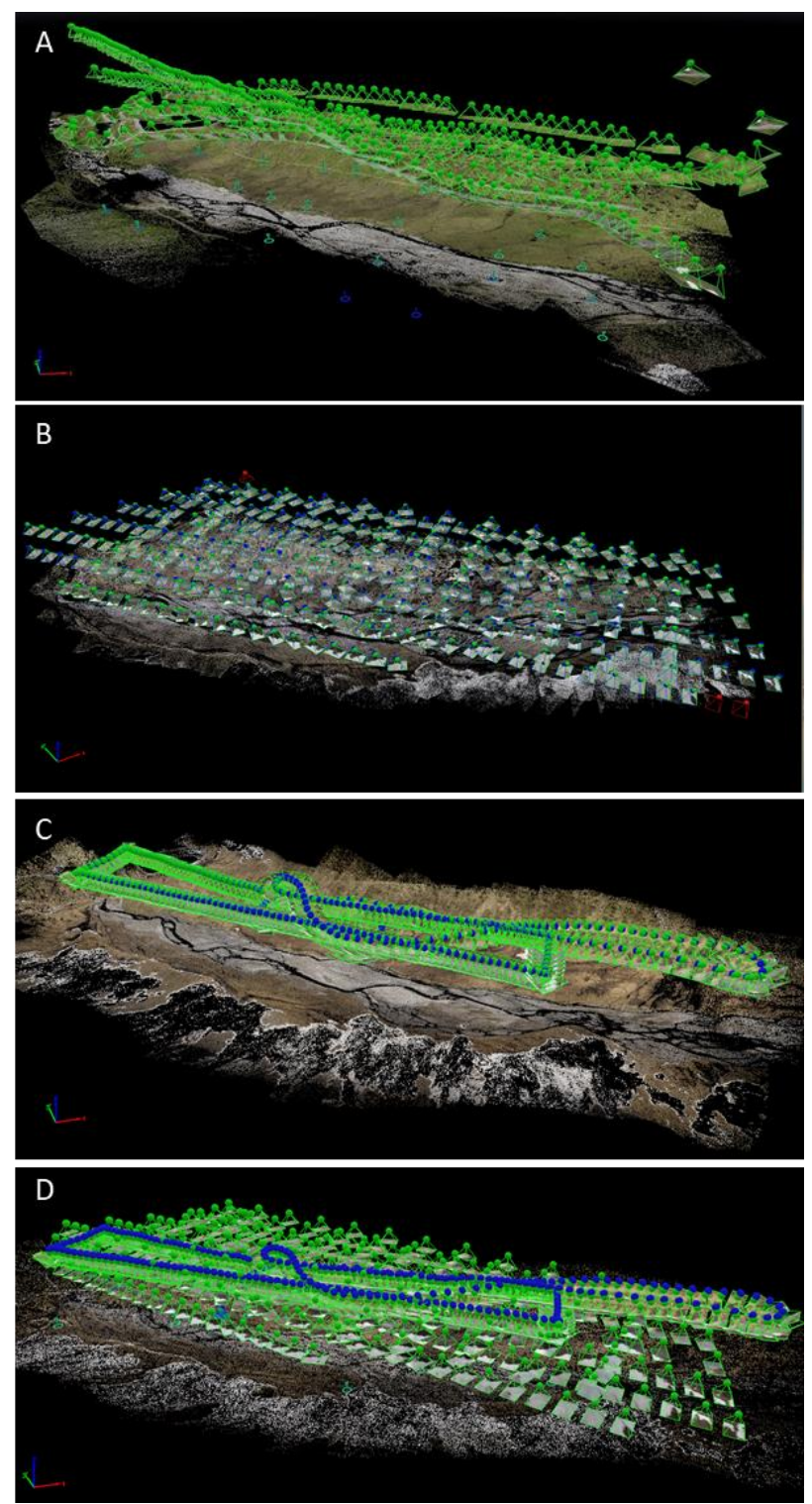

Figure 8. Image blocks after image orientation for: 2015 fixedwing flight (A); 2019 Phantom4 imagery (B); 2019 RiCOPTER imagery (C); 2019 combined image block (D).

Despite the unstructured image acquisition in 2015, the Image orientation shows acceptable accuracies which are only slightly poorer than the image block acquired in 2019. The accuracy obtained from the RiCOPTER images is noticeably lower due to a weaker block geometry. Table 4 also shows the results of the triangulation for the Phantom4 block based on Agisoft Metashape and Pix4D Mapper software. With an RMSE below
$1 \mathrm{~cm}$, the Metashape results seem overly optimistic but no check points were available in this analysis for validation. The unusual opportunity to combine Phantom4 and RiCOPTER images created a comprehensive image block, which provided the most complete coverage of the area of interest. However, as the combination of Phantom4 and RiCOPTER images was computationally expensive and time consuming, only the results of the Phantom4 flight were used for subsequent analyses.

\begin{tabular}{|l|c|c|c|c|c|c|}
\hline \multicolumn{3}{|c|}{ Triangulation } & \multicolumn{3}{c|}{ RMSE (m) } \\
\cline { 2 - 7 } & Img. & GCP & CP & X & Y & Z \\
\hline 2015 Fixed-wing & 260 & 13 & & 0.037 & 0.032 & 0.041 \\
Pix4D & & & 8 & 0.036 & 0.022 & 0.066 \\
2019 Phantom4 & 331 & 11 & & 0.007 & 0.006 & 0.005 \\
Agisoft Metashape & & & & & & \\
2019 Phantom4 & 331 & 7 & & 0.012 & 0.020 & 0.011 \\
Pix4D & & & 4 & 0.023 & 0.022 & 0.046 \\
2019 Ricopter & 604 & 7 & & 0.048 & 0.055 & 0.039 \\
Pix4D & & & 3 & 0.064 & 0.135 & 0.106 \\
2019 Combination & 936 & 8 & & 0.024 & 0.027 & 0.020 \\
Pix4D & & & 6 & 0.024 & 0.028 & 0.030 \\
\hline
\end{tabular}

Table 4. Results of image orientation

\subsubsection{Photogrammetric and LiDAR point clouds comparison}

With its expected high accuracy and density, the LiDAR point cloud was used as the reference dataset to assess the quality of the photogrammetric point clouds. A qualitative assessment of the point clouds derived from the Phantom4 image block showed almost complete coverage with low noise for both Agisoft Metashape and Pix4D Mapper. In contrast, the LiDAR model had some data voids, which were generally not present in the photogrammetric point clouds. These were primarily in snowcovered areas. Further analysis estimated a mean point density of 157 and 190 points $/ \mathrm{m}^{2}$ for the point clouds derived from Metashape and Pix4D-Mapper, respectively. The LiDAR point cloud had significantly higher point density of 556 points $/ \mathrm{m}^{2}$ after removal of duplicate points within a minimum distance of $1 \mathrm{~cm}$. Figure 9 shows the textured point clouds from Pix4DMapper and LiDAR, together with their point density analysis.

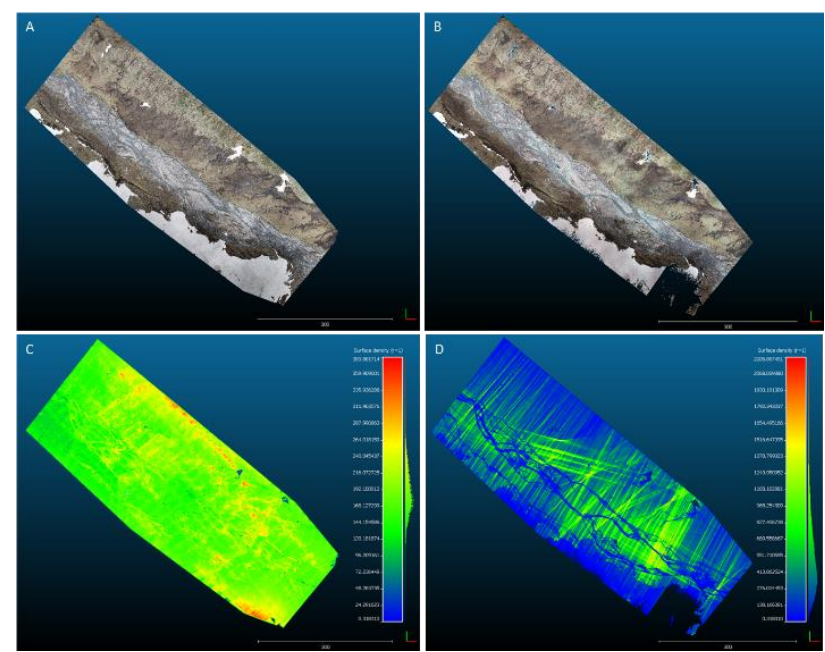

Figure 9. Textured point clouds from photogrammetry (A) and LiDAR (B) with corresponding maps of point density (C, D).

The photogrammetrically derived point clouds had a relatively even distribution with higher point densities on steep slopes and 
small voids over water bodies and snow-covered areas. The bright green in the image marks an average point density of around 190 points $/ \mathrm{m}^{2}$. In comparison, the LiDAR point cloud shows an uneven density distribution with high concentrations of points along characteristic scanlines. While the blue regions indicate point density of approximately 200 points $/ \mathrm{m}^{2}$, the bright green scanlines display densities of larger than 550 points $/ \mathrm{m}^{2}$.

A cloud comparison between the point clouds derived from Agisoft Metashape and Pix4D Mapper revealed a bias of $5.1 \mathrm{~cm}$ with a standard deviation of $2.6 \mathrm{~cm}$. The difference image shows larger disparities along morphological features like steep slopes and the river channels (Figure 10, A). This normally suggests inconsistent co-registration between the datasets. A bias in height between models derived by Agisoft and Pix4D was previously reported by Przybilla et al., (2019); the reasons for this bias remain unknown. Mixing both point clouds would influence the subsequent analysis, thus only the Pix4D model was used.
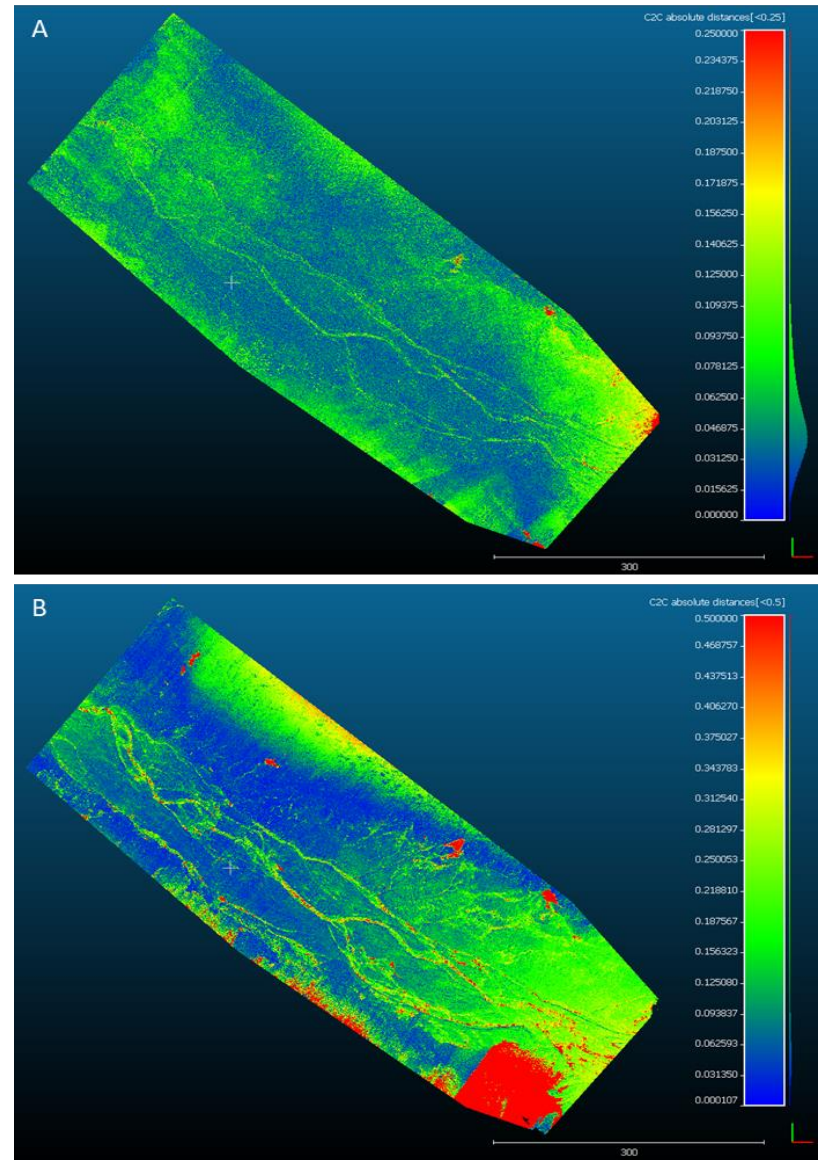

Figure 10. Point cloud differences between Agisoft and Pix4D model (A); Pix4D and LiDAR (B)

The comparison of the PiX4D and the LiDAR models showed a bias of $11 \mathrm{~cm}$ with a standard deviation of $12 \mathrm{~cm}$. Figure 10, B shows the difference image between both datasets. The red areas mark regions with missing data in the LiDAR model. Topographic features can clearly be identified, which is similar to the difference image between the photogrammetric models. There was a good agreement in the flat regions of the valley (blue) and increasing height differences on steeper slopes and the edges of the area of interest. These correlate with regions, which lack GCPs.

\subsection{LiDAR simulation}

The simulated point clouds for optimised UAV-borne and terrestrial LiDAR data acquisitions are shown in Figure 11. These provided a good trade-off between dataset completeness, point density and effort. Simulations of several sample flight trajectories revealed a single flight path at a height of $100 \mathrm{~m}$ would provide a sufficient level of information about the river-channel topography. Similarly, several combinations of data collection strategies were tested for the terrestrial laser scanning survey, suggesting a minimum of five scanning locations would be required to cover the investigated area.

The simulations allowed comparison of the two approaches. The terrestrial survey provided a greater level of detail in the riverbank, which could facilitate a more detailed surface change analysis. However, it is evident from Figure 11 that the terrestrial survey would underrepresent the riverbank top as a result of occlusion unless further scanning positions were used. Such data acquisition simulations can therefore not only help optimise the data collection but help decide which laser scanning approach is most appropriate for a given study area in terms of the required level of detail, coverage area and available time. Whilst the UAV-borne survey would only take several minutes, the terrestrial survey would require several hours for completion.
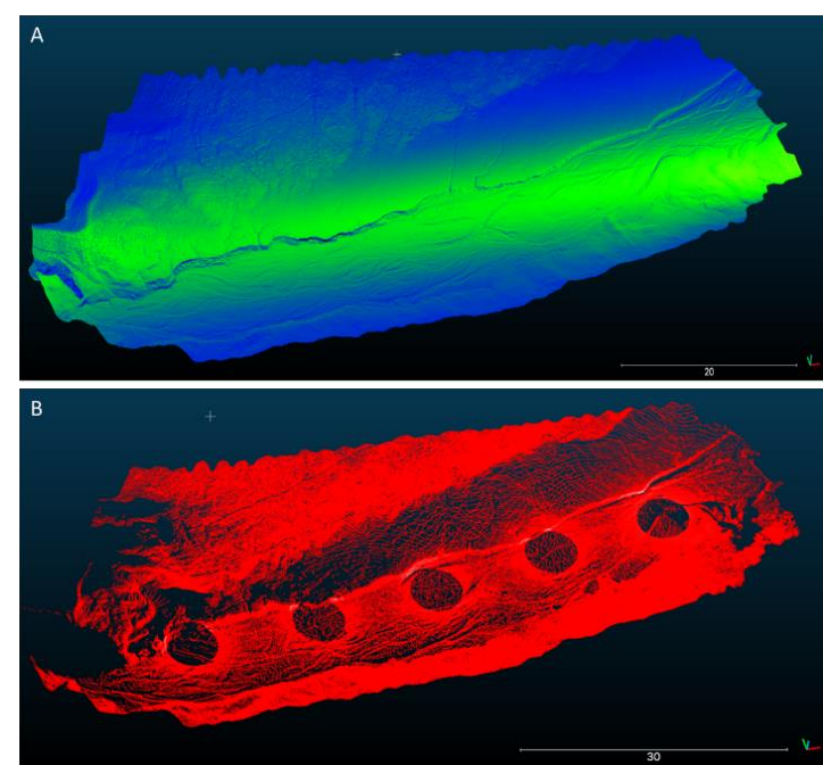

Figure 11. Simulated point clouds of the optimised UAV-borne VUX-1UAV (A) coloured by point density and terrestrial Riegl VZ-400 (B) surveys

\subsection{D surface change analysis}

The 3D surface change analysis revealed a highly dynamic character in the investigated area of the riverbed (Figure 12). A relocation of river channels was indicated by a shifting of areas of accumulation and erosion. Moreover, predominantly positive surface changes along the riverbank indicate a bank failure due to lateral undercutting by the river channel.

The lowest level of detection threshold values $(0.32 \mathrm{~m}-0.34 \mathrm{~m})$ was found for the time intervals 2015/2017 and 2017/2019 (Table 5). Detected changes, which exceeded this threshold, may represent object dynamics that took place with high probability and qualify as surface changes. The level of detection threshold was higher for the 4-year time span. We attribute this increase 
mainly to the higher co-registration error between the datasets from 2015 and 2019 .

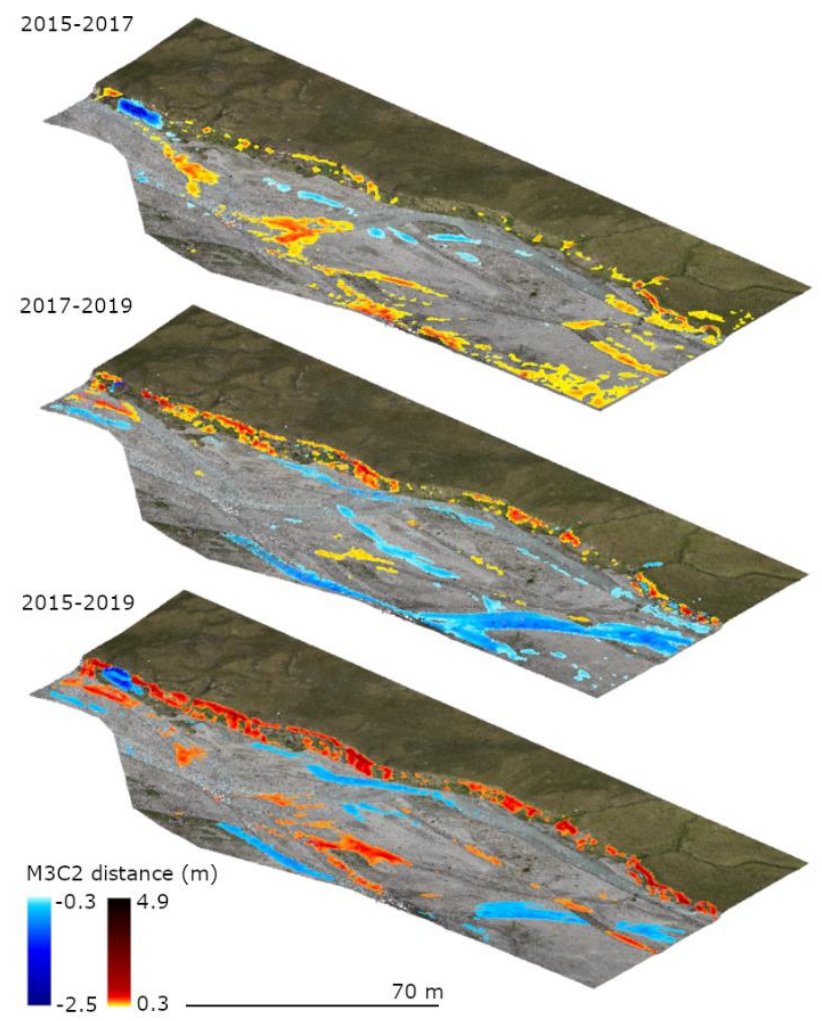

Figure 12. M3C2-calculated distance between 2015, 2017, and 2019 point clouds. Statistically insignificant changes based on confidence interval (see Table 5) were excluded from visualisation.

The detected magnitudes of significant annual surface changes were greater for shorter time spans in both positive and negative directions. Over the investigated 2-year time spans the observed magnitudes were 0.25 and $0.21 \mathrm{~m}$ in the positive and -0.27 and $-0.28 \mathrm{~m}$ in the negative directions, whilst for the 4-year time span they were $0.16 \mathrm{~m}$ and $-0.15 \mathrm{~m}$. These differences in annual surface change rates might point to processes partly counteracting and compensating each other over a longer time frame. This suggests the erosion and accumulation dynamics were aggregated in the 4-year surface change signal and that better decomposition can be achieved utilising shorter time intervals.

\begin{tabular}{|c|c|c|c|}
\hline & $2015 /$ & $2017 /$ & $2015 /$ \\
2017 & 2019 & 2019 \\
\hline $\begin{array}{c}\text { Level of detection threshold [m] } \\
\text { Number of all points > level of } \\
\text { detection [\%] }\end{array}$ & 0.32 & 0.34 & 0.46 \\
$\begin{array}{c}\text { Mean positive significant surface } \\
\text { change [m] }\end{array}$ & 0.42 .14 & 18.24 & 13.24 \\
$\begin{array}{c}\text { Mean negative significant surface } \\
\text { change [m] }\end{array}$ & -0.55 & -0.54 & -0.60 \\
$\begin{array}{c}\text { Mean positive significant annual } \\
\left.\text { surface change rate [m a }{ }^{-1}\right] \\
\text { Mean negative significant annual } \\
\left.\text { surface change rate [m a } \mathrm{a}^{-1}\right]\end{array}$ & 0.21 & 0.25 & 0.16 \\
\hline
\end{tabular}

Table 5. Surface changes detected with M3C2

\section{CONCLUSIONS}

This study tested the applicability of topographic models derived using UAV-borne photogrammetry and LiDAR for multi-temporal monitoring of river-channel morphology. We focused on the data acquisition and processing workflow, highlighting encountered challenges and shortcomings. Additionally, we demonstrated how LiDAR data acquisition simulations can help decide which laser scanning approach to use and help optimise data collection to ensure full coverage with desired level of detail.

Comparison of point clouds derived using photogrammetric principles and UAV-borne LiDAR revealed differences in points distribution. In contrast to the photogrammetric models, the LiDAR dataset had uneven distribution with high concentrations of points along characteristic scanlines. Although LiDAR offered significantly higher point density, it had large data voids in the snow-covered areas, which were generally not present in the photogrammetric point clouds.

To highlight the differences in data acquisition, we simultaneously processed the 2015 imagery from a fixed-wing platform and the 2019 imagery acquired with a multicopter system. Even though flight lines in the 2015 dataset were unstable with many images lacking quality and experiencing motion blur, the image orientation showed acceptable accuracies that were only slightly poorer than the image block acquired in 2019. The 2019 Phantom4 dataset was processed using two commercial software packages, Pix4D Mapper and Agisoft Metashape. A comparison of the resultant point clouds revealed a bias of $5.1 \mathrm{~cm}$ with a standard deviation of $2.6 \mathrm{~cm}$, showing larger disparities along morphological features like steep slopes and the river channels. Although the reasons for this bias are unknown, a similar height disparity between Agisoft and Pix4D point clouds was previously reported by Przybilla et al. (2019).

Lastly, we performed a 3D point cloud-based analysis of changes in river-channel morphology based on photogrammetric point clouds from 2015, 2017 and 2019. The analysis showed a highly dynamic character of the riverbed in terms of relocation of river channels and failure of riverbanks due to lateral undercutting. Additionally, temporal variations in annual magnitudes of surface change rates were observed for different time spans of observation, suggesting the interaction of erosion and accumulation dynamics are better captured with more frequent monitoring.

\section{ACKNOWLEDGEMENTS}

We thank the organisational committee of the Innsbruck Summer School of Alpine Research 2019; Magnus Bremer, Martin Rutzinger, the Remote Sensing and Geomatics group of the Austrian Academy of Science and the University of Innsbruck for the RiCOPTER data acquisition and processing.

Many thanks to our mentor Marco Scaioni for his commitment to pursue this project since the first summer school. Most of all, we would like to thank the participants of the previous summer school editions in 2015 and 2017 for their work and dedication, which paved the way for this study. 


\section{REFERENCES}

Babbel, B.J., Olsen, M.J., Che, E., Leshchinsky, B.A., Simpson, C., Dafni, J., 2019. Evaluation of Uncrewed Aircraft Systems' Lidar Data Quality. ISPRS Int.J. Geo-Inf. 8, 532, doi: 10.3390/ijgi8120532

Bechtold, S., Höfle, B., 2016. HELIOS: A multi-purpose LiDAR simulation framework for research, planning and training of laser scanning operations with airborne, ground-based mobile and stationary platforms. ISPRS Ann. Photogramm. Remote Sens. Spatial Inf. Sci., III-3, pp. 161-168.

Eltner, A., Kaiser, A., Castillo, C., Rock, G., Neugirg, F., Abellán, A., 2016. Image-based surface reconstruction in geomorphometry; merits, limits and developments. Earth Surf. Dyn. 4, 359-389, doi: 10.5194/esurf-4-359-2016.

Chiabrando, F., Nex, F., Piatti, D., Rinaudo, F. (2011) UAV and RPV systems for photogrammetric surveys in archaeological areas: two tests in the piedmont region (Italy). J. Archaeological Sci., 38 (2011), pp. 697-710.

Dall'Asta, E., Forlani, G., Roncella, R., Santise, M., Diotri, F., Morra di Cella, U., 2017. Unmanned Aerial Systems and DSM matching for rock glacier monitoring. ISPRS J. Photogramm. Remote Sens 127, 102-114, doi: 10.1016/j.isprsjprs.2016.10.003.

Giordan, D., Manconi, A., Remondino, F., Nex, F., 2017. Use of unmanned aerial vehicles in monitoring application and management of natural hazards. Geomatics Nat. Haz. Risk 8(14), doi:10.1080/19475705.2017.1315619.

Gómez-Gutiérrez, Á., De Sanjosé-Blasco, J.J. De MatíasBejarano, J. Berenguer-Sempere, F., 2014. Comparing Two Photo-Reconstruction Methods to Produce High Density Point Clouds and DEMs in the Corral del Veleta Rock Glacier (Sierra Nevada, Spain). Remote Sens., 6, 5407-5427.

Hogan, D.L., Luzi, D.S., 2010. Channel geomorphology: fluvial forms, processes, and forest management effects. In: Pike R.G., Redding, T.E., Moore, R.D., Winker, R.D., Bladon, K. (eds) Compendium of forest hydrology and geomorphology in British Columbia, vol 1 of 2. B.C. Land management handbook no. 66, Forest science Victoria, Canada, pp 331-372.

James, M.R., Robson, S., 2014. Mitigating systematic error in topographic models derived from UAV and ground-based image networks. Earth Surf. Process. Landforms 39, 1413-1420, doi: 10.1002/esp.3609.

James, M.R., Robson, S., d'Oleire-Oltmanns, S., Niethammer, U. 2017. Optimising uav topographic surveys processed with structure-from-motion: Ground control quality, quantity and bundle adjustment. Geomorph. 280, 51-66.

Koci, J., Jarihani, B., Leon, J.X., Sidle, R.C., Wilkinson, S.N., Bartley, R., 2017. Assessment of UAV and Ground-Based Structure from Motion with Multi-View Stereo Photogrammetry in a Gullied Savanna Catchment. ISPRS Int. J. Geo-Inf., 6, 328.

Lague D., Brodu N., Leroux J., 2013. Accurate 3D comparison of complex topography with terrestrial laser scanner: application to the Rangitikei canyon (N-Z). ISPRS J Photogramm Remote Sens 82, 10-26, doi: 10.1016/j.isprsjprs.2013.04.009.

Longoni, L., Papini, M., Brambilla, D., Barazzetti, L., Roncoroni, F., Scaioni, M., Ivanov, V.I., 2016. Monitoring Riverbank Erosion in Mountain Catchments Using Terrestrial Laser Scanning. Remote Sens. 8(3), 241, doi: $10.3390 / \mathrm{rs} 8030241$.
Mayr, A., Bremer, M., Rutzinger, M., Geitner, C., 2019. Unmanned aerial vehicle laser scanning for erosion monitoring in alpine grassland. ISPRS Ann. Photogramm. Remote Sens. Spatial Inf. Sci., IV-2/W5, 405-412, doi: 10.5194/isprs-annalsIV-2-W5-405-2019.

Pepe, M., Fregonese, L., Scaioni, M., 2018. Planning Airborne Photogrammetry and Remote-Sensing Missions with Modern Platforms and Sensors. Eur. J. Remote Sens., 51(1), 412-435, doi: 10.1080/22797254.2018.1444945.

Przybilla, H.-J., Gerke, M., Dikhoff, I., Ghassoun, Y., 2019. Investigations on the Geometric Quality of Cameras for UAV Applications using the high precision UAV test field Zollern Colliery. Int. Arch. Photogramm. Remote Sens. Spatial Inf. Sci., XLII-2/W13, 531-538, doi: 10.5194/isprs-archives-XLII-2W13-531-2019.

Pfeiffer, J., Scaioni, M., Rutzinger, M., Adams, M., Graf, A., Sotier, B., Höfle, B., Lindenbergh, R., Oude Elberink, S., Pirotti, F., Bremer, M., Zieher, T., Hämmerle, M., Wujanz, D. (2019): Terrestrial and unmanned aerial vehicle images of the Rotmoos valley bottom near Obergurgl, Austria with coordinates of corresponding ground control points acquired during the Innsbruck Summer School of Alpine Research 2015 and 2017. Inst. of Geography, Univ. of Innsbruck, PANGAEA, doi: 10.1594/PANGAEA.898939.

Rutzinger, M., Höfle, B., Lindenbergh, R., Oude Elberink, S., Pirotti, F., Sailer, R., Scaioni, M., Stötter, J., Wujanz, D., 2016. Close-Range Sensing Techniques in Alpine Terrain. ISPRS Ann. Photogramm. Remote Sens. Spat. Inf. Sci. III-6, 15-22, doi: 10.5194/isprs-annals-III-6-15-2016.

Rutzinger, M., Bremer, M., Höfle, B., Hämmerle, M., Lindenbergh, R., Oude Elberink, S., Pirotti, F., Scaioni, M., Wujanz, D., Zieher, T., 2018. Training in Innovative Technologies for Close-Range Sensing in Alpine Terrain. ISPRS Ann. Photogramm. Remote Sens. Spat. Inf. Sci. IV-2, 239-246, doi: 10.5194/isprs-annals-IV-2-239-2018.

Rutzinger, M. and Heinrich, K. (eds), 2019. Close Range Sensing Techniques in Alpine Terrain. Proceedings of the Innsbruck Summer School of Alpine Research 2019, 16.-22.06.2019 in Obergurgl, Austria. IGF-Forschungsberichte, 8, doi: 10.1553/IGF-8.

Smith, M.W., Carrivick, J.L., Quincey, D.J., 2016. Structure from motion photogrammetry in physical geography. Progr. Phys. Geogr. 40, 247-275, doi: 10.1177/0309133315615805.

Westoby, M.J.; Brasington, J.; Glasser, N.F.; Hambrey, M.J.; Reynolds, J.M., $2012 . \quad$ 'Structure-from-Motion' photogrammetry: A low-cost, effective tool for geoscience applications. Geomorph. 179, 300-314, doi: 10.1016/j.geomorph.2012.08.021.

Woodget, A.S., Carbonneau, P.E., Visser, F., Maddock, I.P. 2015. Quantifying submerged fluvial topography using hyperspatial resolution uas imagery and structure from motion photogrammetry. Earth Surf. Process. Landf., 40, 47-64. 